EPiC Series in Engineering
Volume 3, 2018, Pages 54-61
HIC 2018. 13th International
Conference on Hydroinformatics

\title{
Validation of SMOS-IC Soil Moisture Over Brazilian Semiarid Using In Situ Measurements
}

\author{
Diego Cézar dos Santos Araújo ${ }^{1}$, Suzana Maria Gico Lima Montenegro², \\ Ana Cláudia Villar e Luna Gusmão ${ }^{2}$ and Diogo Francisco Borba Rodrigues ${ }^{2}$ \\ ${ }^{1}$ Federal Rural University of Pernambuco, Recife, Brazil \\ ${ }^{2}$ Federal University of Pernambuco, Recife, Brazil
}

\begin{abstract}
Soil Moisture and Ocean Salinity (SMOS) data validation has been widely performed worldwide since the product became available. However, there are few studies for Brazil. This study focused on the validation of a new version of SMOS product developed by the Institut National de la Recherche Agronomique (INRA) and Center d'Etudes Spatiales de la BIOsphère (CESBIO). One of the advantages of SMOSINRA-CESBIO (SMOS-IC) is that the product is as independent as possible from auxiliary data. The validation was performed at 7 stations located in a semi-arid mesoregion of Pernambuco State, Northeast Brazil, for the year 2016. Bias, root mean square difference (RMSD), unbiased RMSD and the Pearson correlation coefficient (R) were computed between the SMOS-IC data and in situ measurements, considering only the ascending orbit ( 6 am local time). The results were consistent with those found in several studies, including error metrics. The correlation coefficient $(r)$ ranged from 0.53 to 0.86 (mean 0.68 ) and the sensor was able to respond adequately to rainfall events. The results of this study are useful to demonstrate the need to continue validating soil moisture data obtained by remote sensors throughout the state, especially in more rainy locations.
\end{abstract}

\section{Introduction}

Soil moisture is a key variable in water and energy cycles on a global scale. Your knowledge, with high quality measurements, is required for a large number of applications, including short-term weather forecasting, hydrological modeling, agricultural production estimation, drought monitoring and climate change studies [1].

In the last two decades, several studies have shown that soil moisture can be obtained by a wide variety of orbital sensors, including optical, thermal and active/passive microwave instruments. In this sense, Soil Moisture and Ocean Salinity (SMOS), launched in November 2009, was the first satellite 
dedicated specifically to monitor soil moisture, operating in the $\mathrm{L}$ band $(1.4 \mathrm{GHz})$, with a revisit time of 1 to 3 days and accuracy of $0.04 \mathrm{~m}^{3} \mathrm{~m}^{-3}$ [2].

Although SMOS has been extensively calibrated and validated in different locations since its launch [3], there are still few studies for Brazil, especially in the semi-arid region, characterized by low rainfall. This type of study is essential to assess sensor accuracy when compared to in situ measurements and to analyze the sensitivity of its response to rain events, which occur less frequently in the region.

The objective of this study was to compare soil moisture data obtained by SMOS-INRA-CESBIO (SMOS-IC) product, which is a new and improved version of the operational SMOS Level 3 (SMOSL3), with seven stations located in the São Francisco mesoregion, in the semi-arid of Pernambuco State (Northeast Brazil) for a period of one year, using different error metrics to evaluate the sensor performance.

\section{Material and methods}

The São Francisco mesoregion is part of the semi-arid of Pernambuco State (Figure 1), located in the Northeast region of Brazil. With an area of $24,532 \mathrm{~km}^{2}$, this is the mesoregion with the lowest rainfall rates in the state, with an annual average ranging from 400 to $800 \mathrm{~mm}$, while in the state coast these values range from 1000 to $2265 \mathrm{~mm}$ [4].

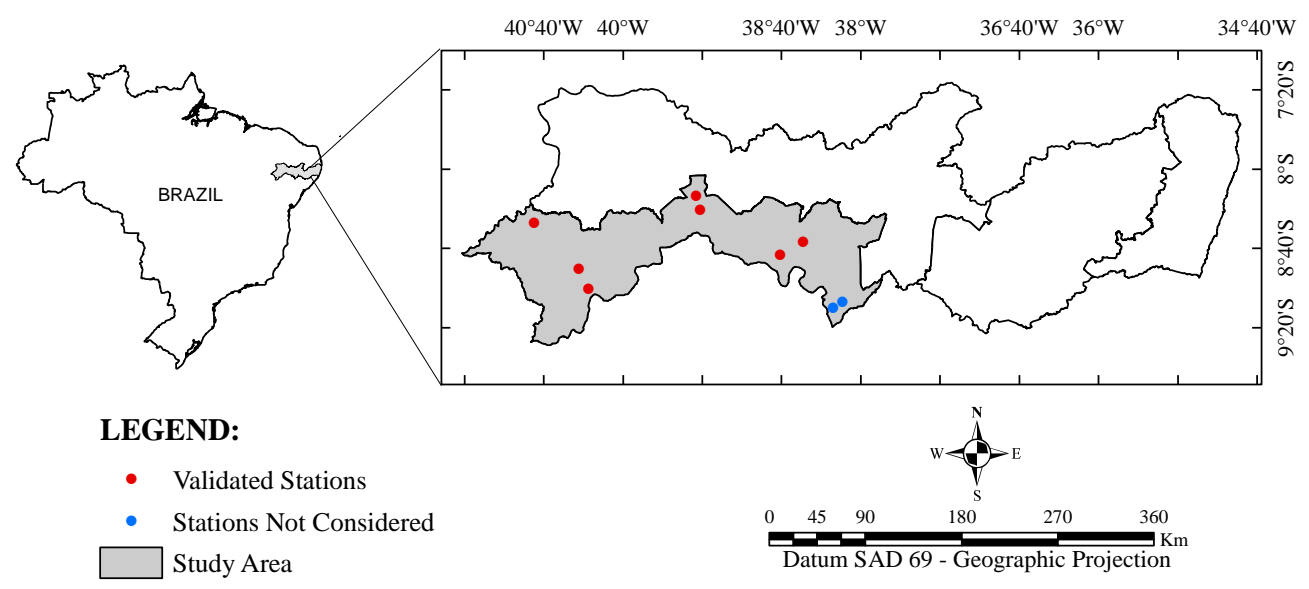

Figure 1: Location of the São Francisco mesoregion in the state of Pernambuco with the stations used in the study (red circles).

The soil moisture monitoring network in the mesoregion is composed by 9 stations of the National Center for Natural Disaster Monitoring and Alerts (CEMADEN), which began collecting data in 2015. Two stations were not considered, since the SMOS-IC data corresponding to these points are not recommended for validations, according to the 'Quality Flag' index provided by the product.

The product used in this study was SMOS-IC, developed by the Institut National de la Recherche Agronomique (INRA) and Center d'Etudes Spatiales de la BIOsphère (CESBIO). The data were provided by INRA/CESBIO. SMOS-IC has emerged as an alternative to the SMOSL3 product provided by the Center for the Treatment of SMOS (CATDS) and differs from the operational SMOSL3 mainly because it is more independent from ancillary data. Furthermore, it does not take into consideration pixel land use and assumes the pixel to be homogeneous. SMOS-IC is based in the original SMOS algorithm, developed by the L-band Microwave Emission of the Biosphere (L-MEB) 
model inversion [5]. Preliminary results were promising and demonstrated their greatest accuracy worldwide in relation to SMOSL3 [6].

Soil moisture data were extracted from the corresponding ground station pixels and then compared. Before the comparisons of the data measured in situ with those estimated by the satellite, an analysis was carried out focusing on the distribution of the spatial patterns of the data in the seven stations of the mesoregion.

To evaluate the performance of the SMOS-IC against in situ stations, the Pearson correlation $(r)$, bias, root mean squared difference (RMSD) and unbiased RMSD (ubRMSD) were calculated. These are the recommended metrics for validation studies of soil moisture data obtained by remote sensors, according to [7]. Only ascending orbit data were considered due to their better performance relative to the descending orbit in several studies [8].

\section{Results and discussion}

At the beginning of 2016, which coincides with part of the rainy season in the São Francisco mesoregion, the highest rainfall indices were recorded in all stations. Considering that the mesoregion is part of the semiarid region of the state, characterized by low rainfall indices combined with high evapotranspiration rates, this type of event, when it occurs, naturally leads to soil moisture peaks that can be easily visualized in box plots, in the form of outliers (Figure 2). The station of Itacuruba presented the highest values of soil moisture, although the distribution of rainfall was quite similar to that recorded in the other stations.

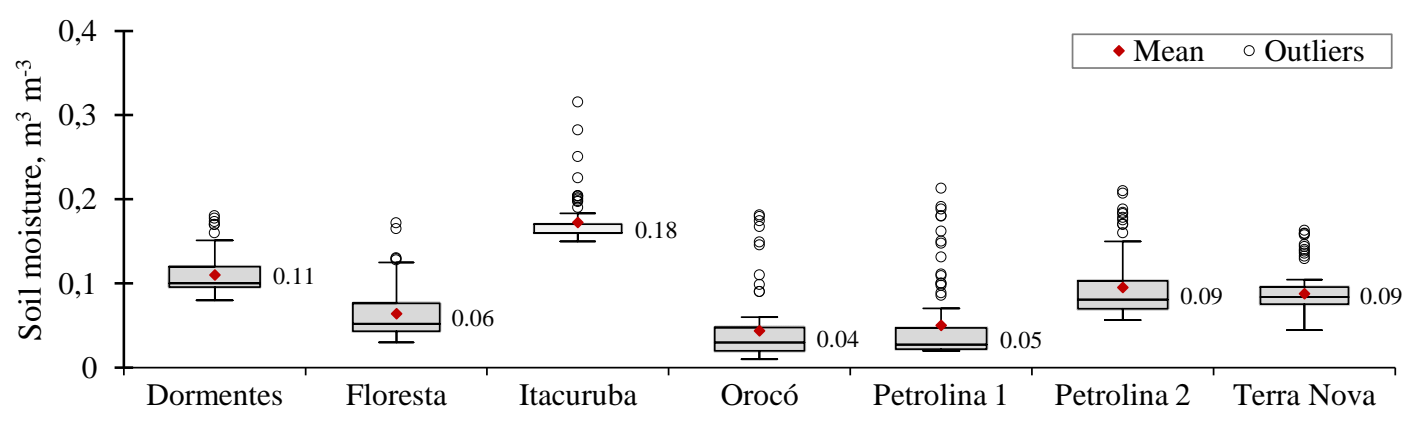

Figure 2: Box plots of mean soil moisture for all stations. The box shows the first and third quartile and the center line shows the median. The mean is represented by red point and its value is shown beside the box.

According to $[9,10]$, in addition to precipitation, the spatial distribution of soil moisture is directly linked to several other factors, such as soil characteristics, climate, topography, vegetation and solar radiation. In particular, soil cover may have a significant effect on water distribution [11]. Thus, the station of Itacuruba is possibly located in an area that favors the wetting of the soil more quickly and withholds rainwater for longer. [12] reinforce that the state of Pernambuco presents a great diversity of soils, with variation of granulometric fractions. It is known that soil texture is a determining factor in the dynamics of water movement, distribution and storage.

The correlation coefficient $(r)$ expresses the relation between two stations (a total of 21 pairs was analyzed). Most of the correlations presented values higher than 0.5 , all significant at $p<0.05$, (Table 1). The correlation matrix is important for analyzing the data and inferring about its spatial pattern. In the São Francisco mesoregion, precipitation has a similar spatial distribution [4], which justifies high values in most correlations, even if located in different cities, since the tendency of soil moisture fluctuation is mainly conditioned by the presence of rainfall and its dynamics. 
Table 1: Correlation coefficients of the mean soil moisture between all the stations.

\begin{tabular}{lccccccc}
\hline & Dormentes & Floresta & Itacuruba & Orocó & Petrolina 1 & Petrolina 2 & Terra Nova \\
\hline Dormentes & & 0.555 & 0.695 & 0.654 & 0.870 & 0.816 & 0.345 \\
Floresta & 0.555 & & 0.687 & 0.645 & 0.476 & 0.425 & 0.224 \\
Itacuruba & 0.695 & 0.687 & & 0.500 & 0.622 & 0.602 & 0.192 \\
Orocó & 0.654 & 0.645 & 0.500 & & 0.751 & 0.664 & 0.515 \\
Petrolina 1 & 0.870 & 0.476 & 0.622 & 0.751 & & 0.883 & 0.479 \\
Petrolina 2 & 0.816 & 0.425 & 0.602 & 0.664 & 0.883 & & 0.494 \\
Terra Nova & 0.345 & 0.224 & 0.192 & 0.515 & 0.479 & 0.494 & \\
\hline
\end{tabular}

However, as already mentioned, the spatial variation of soil moisture is normal and expected, considering its high dependence by other factors besides rainfall. [13], analyzing spatial patterns of soil moisture also in 7 stations before performing comparisons with SMOS, have identified similar $r$ values, above 0.5 in most cases. In this case, all the stations were closer, considering that it is an agricultural area. The results found by the authors show the high soil moisture variability, even in reduced spatial scale.

The temporal distribution of soil moisture data obtained by SMOS-IC product followed the trend of in situ data. Although the mesoregion is marked by very low rainfall indices, which makes it difficult to see this pattern clearly, it is noted that SMOS-IC responds to rainfall events, especially those occurring in the first weeks of the year.

Most of the studies carried out with SMOS occur in regions with higher rainfall indices, which allows to analyze and discuss more accurately the uncertainties of the satellite during rainfall events [14], even in South America [15]. However, it is interesting to note that the product can follow a trend quite similar to the in situ data, even in a prolonged dry period.

Figure 3 shows the validations performed in four stations. Peaks in the SMOS-IC data are common when there are more intense rainfall, generating a soil moisture signature superior to that recorded by the in situ stations, which shows the high sensitivity of the sensor and its rapid response to increase in the surface soil moisture during periods of rainfall. In fact, it is common for SMOS to present more pronounced peaks than the in situ data in the presence of rainfall. This same pattern has already been widely identified in several studies around the world $[13,6]$.

(a)

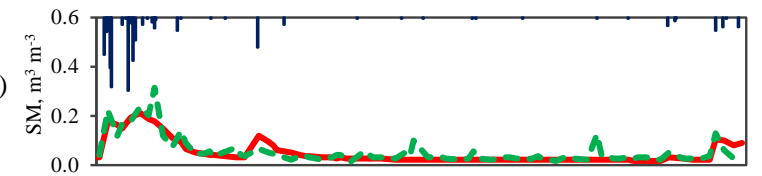

(b)

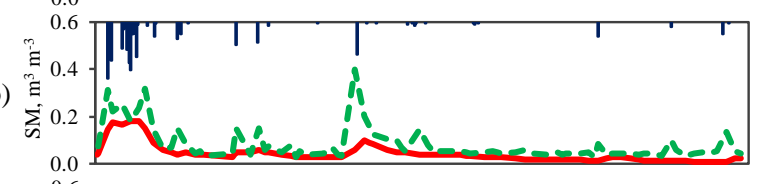

(c)

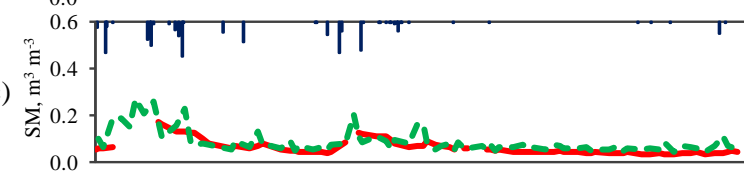

(d)

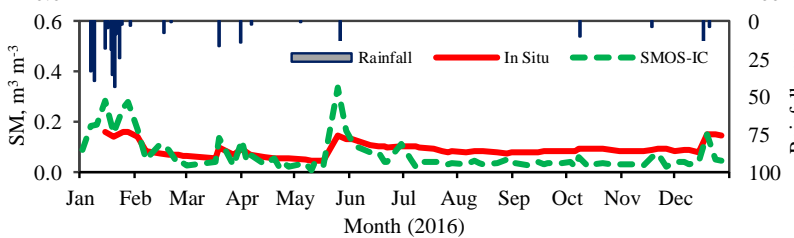

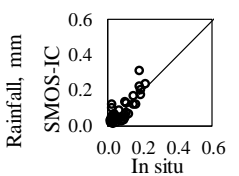
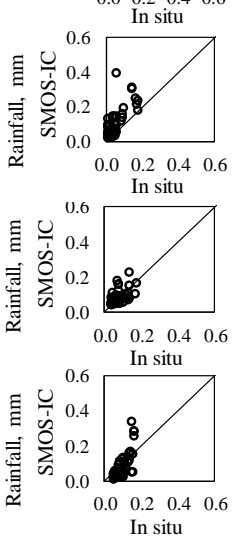

Figure 3: Temporal evolution of SMOS-IC soil moisture compared to the in situ observations at 4 stations.

(A) Petrolina-1, (B) Orocó, (C) Floresta and (D) Terra Nova. SM - Soil Moisture. 
It is important to note that SMOS-IC is an alternative and improved version of the operational SMOSL3 [5]. Thus, much of the data that is outside the satellite's accuracy range is automatically filtered during reprocessing. Preliminary tests performed with SMOSL3, which were not presented in this study, show that the latter product tends to present higher peaks than SMOS-IC. These peaks are usually associated with high values of Data Quality Index (DQX) and Radio Frequency Interference (RFI), which are indices used to evaluate the quality of the data and represents the uncertainty of the retrieval [16]. When this occurs, data filtering is recommended to avoid validation uncertainties.

The mean value of bias for the 7 stations was $0.022 \mathrm{~m}^{3} \mathrm{~m}^{-3}$ (Figure 4), indicating that SMOS-IC underestimated the soil moisture data when compared to the in situ measurements, as also observed by [5,17], although the inverse occurred during precipitation peaks in most cases. The values of RMSD and ubRMSD ranged from $0.031-0.092 \mathrm{~m}^{3} \mathrm{~m}^{-3}$ and $0.0298-0.0545 \mathrm{~m}^{3} \mathrm{~m}^{-3}$, respectively, similar to those found by [9] in China using SMOSL3 product. The stations of Dormentes and Itacuruba presented the highest RMSD and bias values. In both cases, the in situ soil moisture data were higher than those recorded by SMOS-IC. These were the stations that presented the highest soil moisture means in the mesoregion, being superior to the others.

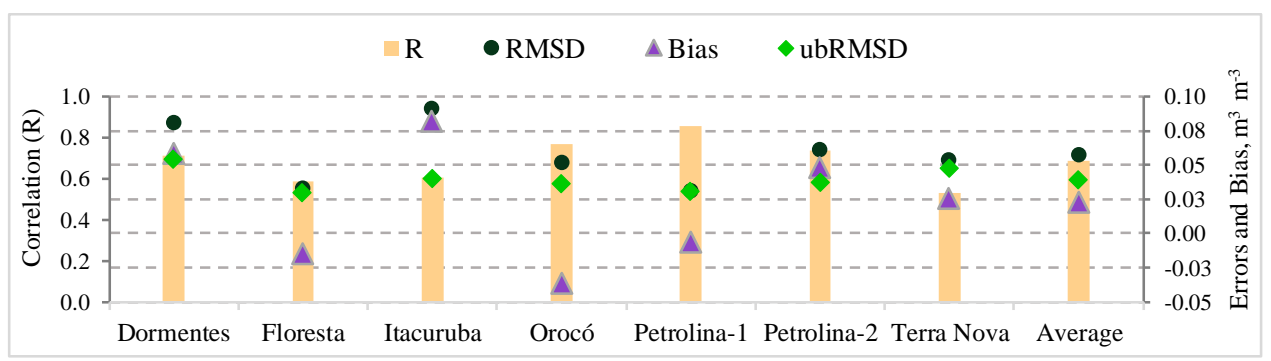

Figure 4: Bar plots of the comparison results between SMOS-IC soil moisture and in situ measurements at each station.

The RMSD, according to [7], tends to be larger than ubRMSD, since the RMSD is affected by the presence of bias or the amplitude of fluctuation of the satellite retrieval. Therefore, in studies of validation of orbital sensor data from in situ measurements, ubRMSD is used as a complement.

The cumulative probability of soil moisture from the satellite and in situ data, in the four stations shown above, is represented in Figure 5. The stations of Petrolina-1 (A) and Floresta (B) presented similar distribution for the two series (in situ and SMOS-IC), which is expected, since the bias values were lower. At the stations of Orocó (C) and Terra Nova (D), where the errors were more expressive, there is a greater distance from the accumulated data observed and estimated by SMOS-IC. The highest peaks of soil moisture recorded by SMOS-IC during the rainfalls (Figure 3) naturally increased the bias in these stations, which led to this behavior. In the case of Orocó station, there is also the fact that the satellite has overestimated the soil moisture. In the Terra Nova station, there was the opposite, especially in the driest period.

A.

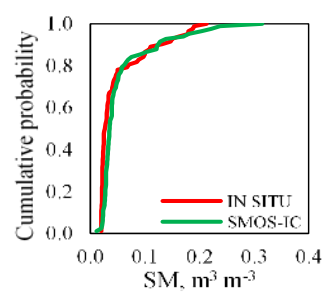

B.

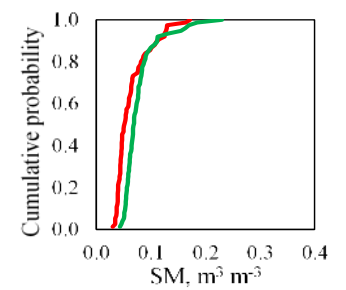

C.

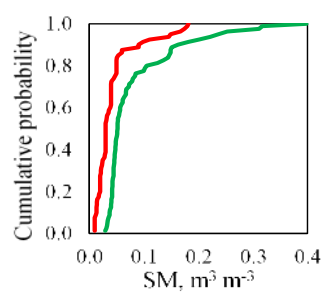

D.

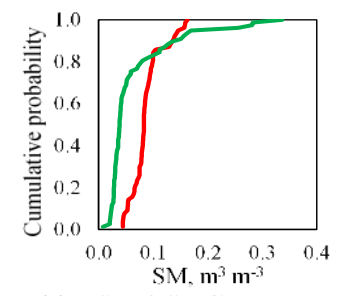

Figure 5: Cumulative probability of soil moisture data obtained in situ and estimated by SMOS-IC. A Petrolina; B - Floresta; C - Orocó; D - Terra Nova. 
Some authors $[18,19,20]$ have already successfully used techniques based on the cumulative distribution function matching $(\mathrm{CDFm})$ to reduce bias between soil moisture data collected in situ and estimated by remote sensors. Thus, it is possible to rescale the satellite time series to match with in situ observations. Among these techniques, the piecewise linear interpolation and fitted polynomials are widely used, especially when there are large number of errors between the two series.

Figure 6 shows the soil moisture distribution maps based on SMOS-IC data for the wettest (January) and the driest (September) months, as well as the Normalized Difference Vegetation Index (NDVI), obtained from the product MOD13A3 of the Moderate Resolution Imaging Spectroradiometer (MODIS) sensor, aboard the TERRA satellite, with resolution of $1 \mathrm{~km}^{2}$. As there was no large temporal variation of soil moisture in the mesoregion throughout the year, we chose to display the maps only of these two periods. It's worth noting that the soil moisture maps have the same color scale for the two months.
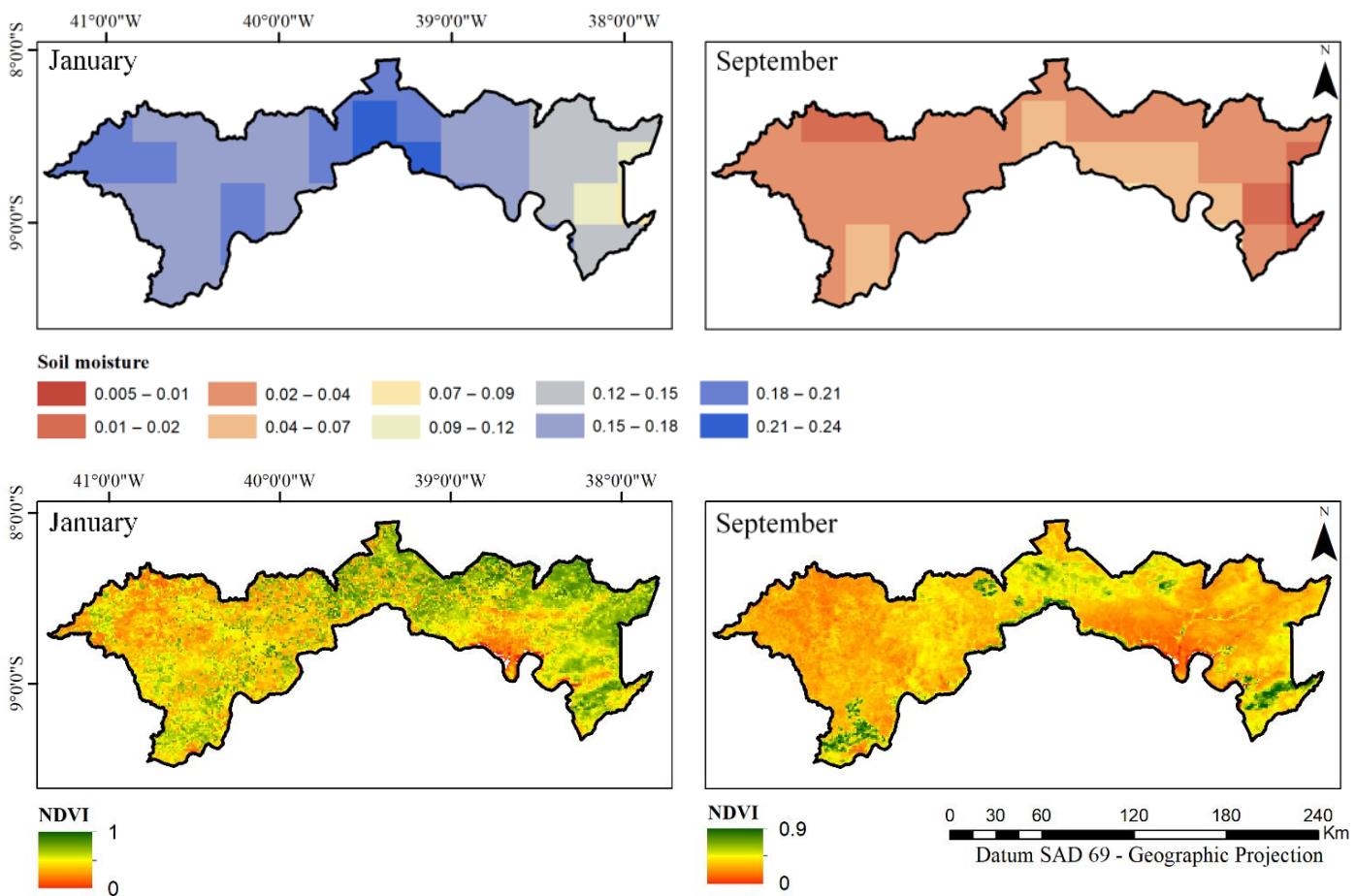

Figure 6: Spatial distribution of soil moisture and NDVI obtained from SMOS and MODIS, respectively.

In January, the mean soil moisture content in the São Francisco mesoregion was $0.164 \mathrm{~m}^{3} \mathrm{~m}^{-3}$, while in September the mean value was $0.032 \mathrm{~m}^{3} \mathrm{~m}^{-3}$. In general, it is possible to notice that the most of the locations that presented higher soil moisture in the wetter month tended to maintain similar pattern in the driest month, considering the large time scale between the two images.

NDVI maps, as well as precipitation, confirm the coherence of the spatial distribution of soil moisture with greater intensity in the month of January. Higher vegetation index was detected in this period compared to the driest month of the year, throughout the mesoregion. It is important to consider that the São Francisco mesoregion is the driest of the state. Thus, even in rainy season, vegetation vigor is lower and late when compared to other mesoregions. As it is a product derived from the operational SMOSL3, SMOS-IC has grid with a $625 \mathrm{~km}^{2}$ sampling. As MOD13A3 has a higher resolution $\left(1 \mathrm{~km}^{2}\right)$, the direct comparison of the spatial distribution of soil moisture as a function of NDVI is limited to this scale. However, the correlation between vegetation indices such as 
NDVI and soil moisture data derived from SMOS has already been proven in some studies, which allowed, through the use of diverse techniques, to downscale the native spatial resolution of SMOS $[21,22]$.

\section{Conclusions}

Most of the studies with SMOS and other satellites are carried out in areas with higher rainfall diversity, which allows to differentiate more clearly the sensor response patterns to the soil moisture variation. Despite the low incidence of rainfall in the validated stations, the similarity of SMOS-IC data with in field measurements over time is noticed, which points out the need to validate the sensor data for other mesoregions of the state, since there is a great variation of rainfall rates in the state and it is perceived that the SMOS-IC responds well to these events. The results presented in this study, however, are important, since they show that SMOS-IC maintains the same tendency of the in situ data, even in the absence of expressive rainfall.

\section{Acknowledgments}

The authors would like to thank Coordination for the Improvement of Higher Education Personnel (CAPES), the National Council for Scientific and Technological Development (CNPq) for the PQ and PDJ scholarships and for the funding of research projects (Universal - MCTI/CNPq N ${ }^{\circ} 14 / 2014$ and MCTI/CNPq/ANA N.23/2015), the Funding Agency for Studies and Projects (FINEP), for the financing of the project REHIDRO 1830, to CAPES by PNPD scholarship, the Foundation for Science and Technology Support of Pernambuco State (FACEPE) for the funding of the research project Consórcio Universitas and by PNPD scholarship, the National Water Agency (ANA), the National Center for Natural Disaster Monitoring and Alerts (CEMADEN) by the data of the in situ stations and J.-P. Wigneron and A. Al-Yaari for providing the version V102 of the SMOS-IC product, which will be distributed by CNES CATDS.

\section{References}

[1] L. Brocca, L. Ciabatta, C. Massari, S. Camici, A. Tarpanelli, Soil Moisture for Hydrological Applications: Open Questions and New Opportunities. Water 9 (2017) 140.

[2] Y. H. Kerr, P. Waldteufel, J.-P. Wigneron, D. Delwart, F. Cabot, J. Boutin, M. J. Escorihuela, J. Font, N. Reul, C. Gruhier, et al., The SMOS Mission: New Tool for Monitoring Key Elements of the Global Water Cycle. Proceedings of the IEEE 98 (2010) 666-687.

[3] C.S. Kang, K.D. Kanniah, Y.H. Kerr, A.P. Cracknell, Analysis of in-situ soil moisture data and validation of SMOS soil moisture products at selected agricultural sites over a tropical region. International Journal of Remote Sensing 37 (2016) 3636-3654.

[4] J.M.C. Possas, M.M. Correa, G.B.A. Moura, P.M.O. Lopes, A.M. Caldas, R.V.P. Fontes Jr., Zoneamento agroclimático para a cultura do pinhão-manso no Estado de Pernambuco. Revista Brasileira de Engenharia Agrícola e Ambiental 16 (2012) 993-998.

[5] J.-P. Wigneron, T. J. Jackson, P. O’Neill, G. Lannoy, P. Rosnay, J. P. Walker, P. Ferrazzoli, V. Mironov, S. Bircher, J. P. Grant, et al., Modelling the passive microwave signature from land surfaces: A review of recent results and application to the L-band SMOS \& SMAP soil moisture retrieval algorithms, 192 (2017) 238-262. 
[6] R. Fernandez-Moran, A. Al-Yaari, A. Mialon, A. Mahmoodi, A. Al Bitar, G. Lannoy, N. Rodriguez-Fernandez, E. Lopez-Baeza, Y. Kerr, J.-P. Wigneron, SMOS-IC: An Alternative SMOS Soil Moisture and Vegetation Optical Depth Product. Remote Sensing 9 (2017) 457.

[7] C. Albergel, L. Brocca, W. Wagner, P. Rosnay, J.C. Calvet, Selection of Performance Metrics for Global Soil Moisture Products: The Case of ASCAT Soil Moisture Product. Remote Sensing of Energy Fluxes and Soil Moisture Content (2013) 427-444.

[8] A. Al-Yaari, J.-P. Wigneron, A. Ducharne, Y. H. Kerr, W. Wagner, G. Lannoy, R. Reichle, A. Al Bitar, W. Dorigo, P. Richaume, A. Mialon, Global-scale comparison of passive (SMOS) and active (ASCAT) satellite based microwave soil moisture retrievals with soil moisture simulations (MERRA-Land). Remote Sensing of Environment 152 (2014) 614-626.

[9] S. Cheng, Z. Li, G. Xu, T. Zhang, Y. Chen, Temporal stability of soil water storage and its influencing factors on a forestland hillslope during the rainy season in China's Loess Plateau. Environ Earth 76 (2017) 539-549.

[10] P. Zhang, M. Shao, Temporal stability of surface soil moisture in a desert área of northwestern China. Journal of Hydrology 505 (2013) 91-101.

[11] A. A. de A. Montenegro, J. R. C. B. Abrantes, J. L. M. P. Lima, T. E. M. Santos, Impact of mulching on soil water dynamics under intermittent simulated rainfall. Catena 109 (2013) 139149.

[12] C. M. Biondi, C. W. A. Nascimento, A. B. Fabricio Neta, Teores naturais de bário em solos de referência do estado de Pernambuco. Revista Brasileira de Ciências do Solo, 35 (2011) 18191826.

[13] C. S. Kang, K. D. Kanniah, Y. H. Kerr, A. P. Cracknell, Analysis of in-situ soil moisture data and validation of SMOS soil moisture products at selected agricultural sites over a tropical region. International Journal of Remote Sensing 37 (2016) 3636-3654.

[14] J. Peng; J. Niesel, A. Loew, S. Zhang, J. Wang, Evaluation of Satellite and Reanalysis Soil Moisture Products over Southwest China Using Ground-Based Measurements. Remote sensing 7 (2015) 15729-15747.

[15] R. Niclos, R. Rivas, V. Garcia-Santos, C. Dona, E. Valor, SMOS Level-2 Soil Moisture Product Evaluation in Rain-Fed Croplands of the Pampean Region of Argentina. EEE Transactions on Geoscience and Remote Sensing 54 (2016) 499-512.

[16] J. Martínez-Fernández, A. González-Zamora, N. Sánchez, A. Gumuzzio, C. M. Herrero-Jiménez, Satellite soil moisture for agricultural drought monitoring: Assessment of the SMOS derived Soil Water Deficit Index. Remote Sensing of Environment, 177 (2017) 277-286.

[17] J. Peng, J. Niesel, A. Loew, S. Zhang, J. Wang, Evaluation of Satellite and Reanalysis Soil Moisture Products over Southwest China Using Ground-Based Measurements. Remote sensing 7 (2015) 15729-15747.

[18] K. Kornelsen, P. Coulibaly, Reducing multiplicative bias of satellite soil moisture retrievals. Remote Sensing of Environment 165 (2015) 109-122.

[19] A. Mishra, T. Vu, A. V. Veettil, D. Entekhabi, Drought monitoring with soil moisture active passive (SMAP) measurements. Journal of Hydrology 552 (2017) 620-632.

[20] L. Brocca, S. Hasenauer, T. Lacava, F. Melone, T. Mora, et al., Soil moisture estimation through ASCAT and AMSR-E sensors: An intercomparison and validation study across Europe. Remote Sensing of Environment 115 (2011) 3390-3408.

[21] O. Merlin, Y. Malbéteau, Y. Notfi, S. Bacon, S. Er-raki, et al., Performance Metrics for Soil Moisture Downscaling Methods: Application to DISPATCH Data in Central Morocco. Remote sensing 7 (2015) 3783-3807.

[22] M. Piles, A. Camps, M. Vall-llosera, I. Corbella, R. Panciera, et al., Downscaling SMOS-Derived Soil Moisture Using MODIS Visible/Infrared Data. IEEE Transactions on Geoscience and Remote Sensing 49 (2011) 3156-3166. 